\title{
A game-theoretical model of multisubject industrial policy
}

\author{
Victoria Akberdina ${ }^{1,2}$, Grigoriy Korovin ${ }^{1}$, and Aleksandra Ponomareva ${ }^{1, *}$ \\ ${ }^{1}$ Institute of Economics of the Ural Branch of the Russian Academy of Sciences, Yekaterinburg, \\ Russia \\ ${ }^{2}$ Ural Federal University, Yekaterinburg, Russia
}

\begin{abstract}
The vector of industrial policy developmen aimed at the transition from the domination of the state to the involvement in its development of all stakeholders is relevant in developed countries. Such an approach requires an additional scientific justification, confirming its feasibility. The purpose and objectives of the paper is the development within the framework of game theory a model of relationships of subjects interested in the industrial policy based on their interests, strategies, areas of conflict and areas of consensus. The study used a multi-subject approach, which implies the existence of a number of independent stakeholders with their own goals and strategies. The methodology of evolutionary game theory (EGT) was used to analyze the interests of the stakeholders of their coincidences and conflicts. The process of formation of industrial policy identified three possible points of equilibrium. The interaction between the state and enterprises is formalized as a game in a normal form, the functions of utility of the players and the equation of replication dynamics are presented. To formalize the problem and finding the equations of the replicative dynamics, we have considered the problem in a general form for the continuous asymmetric games. In terms of content, the results and decisions can be used as a characteristic of the space for the creation of multiple mutually acceptable agreements between real and potential participants in the process of industrial policy formation. It is possible to further analyze the model to obtain a quantitative assessment of the factors that have the greatest impact on the motivation of the interaction participants.
\end{abstract}

\section{Introduction}

One of the main problems in the implementation of industrial policy in Russia is the lack of effective state intervention and the imperfection of the institutions of interaction of the subjects interested in industrial policy. The stakeholders of industrial policy include industrial enterprises, infrastructure, public authorities and local self-government, universities and research institutions, society and public organizations. The inefficiency is more evident in the existence of the hidden mechanisms of lobbying, non-transparent

\footnotetext{
* Corresponding author: alex.ponomareva@gmail.com
} 
mechanisms of support to individual enterprises, the "capture" of governance structures for the industry by major stakeholders of financial-industrial groups and, consequently, reduced level of mutual trust.

The approach based on the management of relations between these entities is one of the most acceptable in the creation of institutional structures and mechanisms for the development and implementation of industrial policy. In our opinion, the direction of industrial policy development from the state to the multi-object one is typical for developed countries and can lead to an effective combination of various mechanisms of vertical or horizontal industrial policy, the use of mechanisms of its formation at certain stages with the use of a broad public consensus.

The understanding of industrial policy can no longer be limited to a set of measures or solutions aimed at stimulating the development of priority sectors of the economy. In our opinion, the actual approach is that it is defined as a system of relations between state and municipal authorities, enterprises, scientific and educational organizations and civil institutions on the formation of structurally balanced competitive industry [13]. In general, in our view, there is a need for more active involvement of new stakeholders in the industrial policy-making process.

\section{Methodology}

Among Russian specialists, who noted the high importance of enhancing intersubjective dialogue about industrial policy, it is possible to note such scholars as: V. M. Polterovich [10], O. A. Romanova [12], V. E. Dementiev [3], Boris Kuznetsov, Yuri Simachev [7], G. I. Idrisov, [5]. Professor A. V. Grebenkin noted the principle of multiobjectivity as a complex web of properties that requires constant updating, and functional compliance as a necessary condition for the evolution of the economic system [2]. Statements about the need to adopt principles that relate to the multisubject approach can be found in other scientists: J. Stigliz [20], C. Hochfeld, C. Kabel [19], A. Andreoni [14], L. Chen, B. Naughton [16], as well as in documents of European state, public and research organizations [17].

Generalization of changes in the dynamics of a model of formation of industrial policy in developed countries allows us to speak about combining «bottom-up» and «top-down» approaches, that is the combination of private initiatives and interests with the state in a complementary basis (table 1).

Table 1. Characteristics of the stages of development of industrial policy in developed countries.

\begin{tabular}{|c|c|c|c|}
\hline & $70-90 s$ & $2000 \mathrm{~s}$ & $\begin{array}{c}\text { Actual directions of } \\
\text { the } 2010 \mathrm{~s}\end{array}$ \\
\hline $\begin{array}{c}\text { Policy } \\
\text { objectives }\end{array}$ & $\begin{array}{c}\text { Specialization and } \\
\text { modernization under the } \\
\text { influence of market forces }\end{array}$ & $\begin{array}{l}\text { Innovation, productivity } \\
\text { increasing }\end{array}$ & $\begin{array}{l}\text { Development of } \\
\text { production networks } \\
\text { and industrial } \\
\text { ecosystems }\end{array}$ \\
\hline Policy model & $\begin{array}{l}\text { Minimum importance of } \\
\text { the state, weakening and/or } \\
\text { elimination of national } \\
\text { institutions }\end{array}$ & $\begin{array}{l}\text { Multilayered policy - } \\
\text { "top-down" and "bottom- } \\
\text { up". Combining public } \\
\text { and private priorities. } \\
\text { Creation of institutions to } \\
\text { stimulate scientific } \\
\text { research }\end{array}$ & $\begin{array}{c}\text { Institutes of } \\
\text { coordination public } \\
\text { and private interests, } \\
\text { their implementation } \\
\text { at different levels. } \\
\text { Regional } \\
\text { development }\end{array}$ \\
\hline
\end{tabular}


The choice of methodology for interaction modeling in the formation of industrial policy, we carry out taking into account a number of existing and emerging features of this process:

1) complication of industrial policy, inclusion of a wider range of participants in the procedures of collecting opinions and making decisions on economic policy;

2) increased participation of business and society representatives in project planning, initiation and selection processes;

3) developing different types of dialogue and agreements in shaping of future sustainable industrial policy;

4) emergence of a dense network of coordination, ensuring the exchange of information between the government, business and other participants;

5) need for coordination of heterogeneous agents in a complex system of relationships and accounting for feedbacks;

6) existence of processes for the accumulation of knowledge about other actors and interaction with them and the corresponding adaptation of their own strategy.

As a result, many intelligent players implement strategies that result in a situation of equilibrium. Moreover, the players in the process gaining valuable experience. They choose options, evaluate the results, perhaps experiment with other options and sometimes make mistakes. The formation of industrial policy is a process of emergence and destruction of agreements, which shifts players towards equilibrium.

This article discusses the prerequisites and possibilities of modeling multi-object policy on the example of game interaction between business and the state. The methodology of evolutionary game theory (EGT) was used to analyze the interests of the subjects of their coincidences and conflicts. This choice is justified by several reasons. First, these methods allow to analyze processes of a system with multiple generations in which there is a continuity of solutions. Secondly, this tool gives the opportunity to quantify equilibrium points and parameters that affect the transition from one equilibrium state to another. The game is presented in a normal form. The formalization of the problem of evolutionary game theory and the possibility of finding Nash equilibria are shown.

EGT is a relatively new field of science that combines the principles of game theory, evolution, and dynamic systems to interpret agent interactions. Among the main requirements that must be met for the analysis of evolutionary games, it should indicate the dynamic nature of the system, that is, players and their strategies must exist for many periods. Thus, it is possible to model evolutionary dynamics. The formalization of a set of stable strategies is sought by the criteria of pure or mixed Nash equilibrium (for symmetric games of the "prisoner's dilemma" type, the set of equilibrium strategies can be found in pure strategies, for asymmetric games - in mixed ones). In general, the game is asymmetric and ideally during the process of evolutionary dynamics there is a point of equilibrium, which reflects the stable state of the strategies chosen by the players.

\section{Formalization of the game}

A sufficient number of studies are devoted to the problem of simulation of evolutionary dynamics in various areas of the economy. In the work of T. Rees [21], the mechanisms necessary for the simulation of evolutionary dynamics are presented, equilibrium functions of players in general and applied to three different games. The mechanisms of finding stable states of the system are considered, the weak and strong sides of the concept of evolutionary game theory are illustrated. The approach to the substantiation of the theoretical foundations of the evolutionary game theory and the substantiation of the concepts of simulation of game situations is described quite similarly in the work of Weibull J. W. [24] From the point of view of the application of the EGT methods, it is worth paying attention to the work of Q. Zhu and Y. Dou [25], which considers the diffusion of technological innovations in the 
automotive industry (also known as a green growth) with the support of the state. Game analysis shows that the costs and benefits of the main enterprises in the implementation of «green» supply chains, as well as subsidies and fines from governments directly affect the benefits of the interaction. To obtain long-term benefits, governments must enact and enforce increasingly stringent environmental regulations and increase related subsidies and fines. This is the way to implement a mutually beneficial strategy between governments and key enterprises in the long term.

The work [23] in a sense is a continuation of the work of 2007 and focuses on modeling the relationship between the state, business and society. Theoretical calculations are applied to real data on the automotive industry in China. The results of the study show that it is better to allocate subsidies to producers than to consumers to stimulate the spread of innovation.

The process of natural selection, which determines how the agents evolve using a particular strategy, called replicator dynamics. The dynamics of the replicator depends on the evolutionary model used and can be represented as a discrete or continuous equation. In general, of course, we should consider a continuous process. In addition, it is more suitable for non-symmetrical games.

Formalize the model in general for an asymmetric game in normal form. For each group of players $\mathrm{x}$ there is a vector $\overrightarrow{\mathrm{x}}$, which consists of $i$ components equal to the frequency of the corresponding group of players. The function $f_{i}(\vec{x})$ describes the state of the group, namely its success must be defined for each $\vec{x}$.

In the asymmetric game of two players, each of them has its own payment matrix, which will reflect the interests of different generations of players. Also, the win function will describe the game and the winnings that occur between different generations.

Suppose that player 1 has n pure strategies defined through s $11, \ldots, \mathrm{s} 1 \mathrm{n}$; and player 2 has $\mathrm{m}$ pure strategies $\mathrm{s} 21, \ldots, \mathrm{s} 2 \mathrm{n}$. Player 1 and player 2 have payoff matrixes A and $\mathrm{B}$ respectively. A vector of strategies for the first player is $\vec{x}$, and for the second $\vec{y}$. Then the function corresponding to the strategy $\mathrm{s} 1 \mathrm{i}$ is equal to $\mathrm{f}_{1 \mathrm{i}}=(\mathrm{Ay})_{\mathrm{i}}$. The average payoff function for the first player will be $\overline{\mathrm{f}}_{1}=\overrightarrow{\mathrm{x}}^{\mathrm{T}} \mathrm{A} \overrightarrow{\mathrm{y}}$.

The payoff for the strategy $s 2 \mathrm{i}$ is $\mathrm{f}_{2 \mathrm{i}}=(\mathrm{Bx})_{\mathrm{i}}$ and the average payoff for the second player is defined as $\overline{\mathrm{f}}_{2}=\overrightarrow{\mathrm{y}}^{\mathrm{T}} \mathrm{B} \overrightarrow{\mathrm{x}}$.

The continuous process of replicating dynamics can be formalized for two-player asymmetric game in normal form, but the dynamic equation must be defined for each player [20].

Thus, we have two differential equations in a general form:

$$
\begin{aligned}
& \left.\dot{x}(t)_{i}=x_{i}\left((A \vec{y})_{1}-\vec{x}^{T} A \vec{y}\right)\right) \\
& \left.\dot{y}(t)_{i}=y_{i}\left((B \vec{x})_{1}-\vec{y}^{T} B \vec{x}\right)\right)
\end{aligned}
$$

It is important to note that Nash equilibria in the game are fixed points of each of the dynamic equations presented above. This means that if players ever reach a state that is Nash's equilibrium, they will stay there.

To model a multisubject policy, it is necessary to formalize the relations of agents in the form of a normal game. Consider the matrix of the game for enterprises in a particular industry and the state in a situation where the government aims economic growth. Payoff 1 is a payoff of the state, payoff 2 for enterprises. Thus, the payoff matrix is equal to:

$$
\mathrm{A}=\left(\begin{array}{cc}
\mathrm{P}+\mathrm{F}-\mathrm{Q} & -\mathrm{C}_{\mathrm{G}}+\mathrm{D} \\
\mathrm{F} & -\mathrm{C}_{\mathrm{G}}
\end{array}\right) \text { и } \mathrm{B}=\left(\begin{array}{cc}
\mathrm{B}+\mathrm{Q}-\mathrm{T} & -\mathrm{D}-\mathrm{C}_{\mathrm{E}} \\
\mathrm{B}-\mathrm{T} & -\mathrm{C}_{\mathrm{E}}
\end{array}\right)
$$

for the state and enterprises respectively.

The probabilities of decision-making for the state and enterprises are $\mathrm{x} ;(1-\mathrm{x})$ and $\mathrm{y} ;(1-\mathrm{y})$, respectively. The matrix of the game in normal form is presented in table 2 . 
Table 2. The matrix of the game in normal form.

\begin{tabular}{|c|c|c|}
\hline State / entities & $\boldsymbol{y}$ & $\boldsymbol{1}-\boldsymbol{y}$ \\
\hline$x$ & $\begin{array}{c}P+F-Q ; \\
B+Q-T\end{array}$ & $\begin{array}{c}-C_{G}+D ; \\
-D-C_{E}\end{array}$ \\
\hline $1-x$ & $F ;$ & $-C_{G} ;$ \\
& $B-T$ & $-C_{E}$ \\
\hline
\end{tabular}

$\mathrm{P}$ - the reward of the state from the transition to a new state; $\mathrm{F}$ - the loyalty that the state receives from enterprises in the transition to a new technological state; $\mathrm{Q}$ - state subsidies to enterprises (deposits); $\mathrm{B}$ - the benefits of enterprises in the transition to a new state; $\mathrm{T}$ - the costs of transition to a new state; $\mathrm{CG}$ - the loss of the state in the long - term in the absence of technological changes; D - a fine that pays the business, refusing technological changes; $\mathrm{CE}$ - the loss of enterprises in the long-term in the absence of technological changes.

Obviously, it is possible to find a Nash equilibrium in mixed strategies and investigate it in terms of dynamics in several time periods. For the case of the formalized game above, the differential equations of the replication dynamics will look as follows:

$$
\begin{aligned}
& \left.\dot{x}=x\left((A \vec{y})_{1}-\vec{x}^{T} A \vec{y}\right)\right) \\
& \left.\dot{y}=y\left((B \vec{y})_{1}-\vec{y}^{T} B \vec{x}\right)\right)
\end{aligned}
$$

As mentioned above, each of the equations reflects the dynamics of the system, exploring which it is possible to obtain information about the equilibrium sets of strategies. The next step is to build utility functions for each player. As the task is to study the model, to stimulate introduction of new technologies by state $(\mathrm{x})$ and applying these changes to enterprises $(\mathrm{y})$, it is necessary to build private utility functions $\left(U_{1 X}\right.$ and $\left.U_{2 y}\right)$ relative to these strategies.

However, to study of the model it is necessary to consider all the particular functions, as well as the average utility functions. According to the model, the state has two strategies - to support (x) and not to support (1-x) producers. The utility functions are, respectively, equal to $\left(U_{1 x}\right.$ and $\left.U_{2 y}\right)$. The average utility function is $\bar{U}_{1}$.

Formalize them:

$$
\begin{aligned}
& \mathrm{U}_{1 \mathrm{X}}=\mathrm{y}(\mathrm{P}+\mathrm{F}-\mathrm{Q})+(1-\mathrm{y})(-\mathrm{CG}+\mathrm{D}) \\
& \mathrm{U}_{1 \mathrm{~N}}=\mathrm{yF}-\mathrm{CG}+\mathrm{y} C \mathrm{C} \\
& \overline{\mathrm{U}}_{1}=\mathrm{xy}(\mathrm{P}+\mathrm{F}-\mathrm{Q})+\mathrm{x}(1-\mathrm{y})(-\mathrm{CG}+\mathrm{D})+(1-\mathrm{x})\left(\mathrm{yF}-\mathrm{C}_{\mathrm{g}}+\mathrm{y} \mathrm{C}_{\mathrm{g}}\right)
\end{aligned}
$$

Enterprises also have two strategies - to implement (y) and not ot implement new technologies (1-y). Consider the utility functions for enterprises: to implement $\left(U_{2 y}\right)$, not to implement $\left(\mathrm{U}_{2 \mathrm{~N}}\right)$, and the average function of utility $\overline{\mathrm{U}}_{2}$. Formilize them:

$$
\begin{aligned}
& U_{2 y}=x(B+Q-T)+(1-x)(B-T)=x Q+B-T \\
& U_{2 N}=x\left(-D-C_{E}\right)+(1-x)\left(-C_{E}\right)=-x D-C_{E} \\
& \bar{U}_{2}=y x Q+y B-y T+(1-y)\left(-x D-C_{E}\right)
\end{aligned}
$$

Thus, it is possible to write a differential equation that will be studied for stability for each of the players.

For the state: 


$$
F(x)=x\left(U_{1 x}-\bar{U}_{1}\right)
$$

For the enterprises:

$$
\mathrm{F}(\mathrm{Y})=\mathrm{y}\left(\mathrm{U}_{1 \mathrm{Y}}-\overline{\mathrm{U}}_{2}\right)
$$

Evolutionary analysis of this game is not trivial. Each player must be represented by separate groups of players whose pairs are randomly drawn from two populations and played against each other. It is also needed to analyze the differential equations, which are essentially replicator dynamics equations, for stability.

Let's take a closer look at some model variables.

Remuneration $\mathrm{P}$ consists of a material and an intangible components, which in turn are determined by the status of the subject. Let's define rewards in the form of:

where

$$
P_{i}=N_{i} q_{i} S_{i}\left(g_{0}+g_{1} \tilde{1}_{i} S_{i}\right) \cdot \frac{r_{i}^{h}}{\sum_{k=0}^{H_{i}} r_{i}^{k} N_{i}^{k}}
$$

$$
\mathrm{r}_{\mathrm{i}}^{\mathrm{h}}=\mathrm{q}_{\mathrm{i}}+\mathrm{r}_{\mathrm{i}} \cdot \mathrm{o}_{\mathrm{i}}^{\mathrm{h}}
$$

In this expression, $\mathrm{N}_{\mathrm{i}} \mathrm{q}_{\mathrm{i}}$ is the sum of all (tangible and intangible) deposits for the $\mathrm{G}_{\mathrm{i}}$ union. The solidarity factor $S_{i} \leq 0$ is a measure of reliability.

The next element in the formula (13) $\left(\mathrm{g}_{0}+\mathrm{g}_{1} \tilde{\mathrm{I}}_{\mathrm{i}} \mathrm{S}_{\mathrm{i}}\right)$ is related to the impact of certain factors on the possible redistribution of deposits. The decrease of remuneration due to administrative costs is an element $g_{0}<1$. The increase of intangible or material remuneration of group activities is determined by the second element. This element is directly proportional to the overall impact $\tilde{\mathrm{i}}_{\mathrm{i}}$ and solidarity $\mathrm{S}_{\mathrm{i}}$.

The distribution coefficients of the renumeration are included in the last term of the formula (13) and are denoted by $r_{i}^{h}$ and $r_{i}^{k}$. The first coefficient $r_{i}^{h}$ includes the statusindependent summand $q_{i}$ and the summand that is proportional to the obligations $r_{i} \cdot o_{i}^{h}$. At the same time, $r_{i}$ acts as a renumeration coefficient. The second coefficient determines the part of the remuneration received by the member of the association with the status $h$.

As a result, the renumeration formula (13) can be transformed into the following form:

$$
\frac{p_{i}^{h}}{p_{i}^{k}}=\frac{r_{i}^{h}}{r_{i}^{k}}
$$

For all memebers of the assotiation $\mathrm{G}_{\mathrm{i}}$ the total renumeration is:

$$
\sum_{\mathrm{h}=0}^{\mathrm{H}_{\mathrm{i}}} \mathrm{N}_{\mathrm{i}}^{\mathrm{h}} \mathrm{p}_{\mathrm{i}}^{\mathrm{h}}=\mathrm{N}_{\mathrm{i}} \mathrm{q}_{\mathrm{i}} \mathrm{S}_{\mathrm{i}}\left(\mathrm{g}_{0}+\mathrm{g}_{1} \tilde{\mathrm{l}}_{\mathrm{i}} \mathrm{S}_{\mathrm{i}}\right)
$$

The component of loyalty $f_{i}$ describes an intengible component associated with the support as a particiant of the assotiation $\mathrm{G}_{\mathrm{i}}$. Let $\mathrm{f}$ is:

which can be justified so.

The effect of the total effect of the $\tilde{I}_{\mathrm{i}} \mathrm{S}_{\mathrm{i}}$ of the association $\mathrm{G}_{\mathrm{j}}$ on loyalty is described by the feedback coefficients of $w_{i j}$. Components $w_{i j} \tilde{I}_{i} S_{i}$ with $j=i$ and $w_{i j}>0$ characterize positive feedback. But the influence of competing groups $G_{j}$ on loyalty within the association $G_{i}$ can be both constructive (if $\mathrm{w}_{\mathrm{ij}}>0$ )), and so deconstructive (если $\mathrm{w}_{\mathrm{ij}}<0$ ). In the latter case, $\mathrm{f}_{\mathrm{i}}$ will decrease. Then a competing association can either positively or negatively affect utilities of another association.

\section{Conclusion}


The article presents a game-theoretical model of interaction between the state and enterprises in a situation where the state initiates the introduction of technological innovations in order to initiate economic growth. On the basis of payoff matrixes, the utility functions of each player and the functions for studying the replicator dynamics are formalized. At the next stage, it is planned to study this system for stability and find points of stable equilibrium by Nash, as well as to quantify the parameters affecting them.

The article is prepared in accordance with the state order of the Federal Agency of Scientific Organizations of Russia for the Institute of Economics of the Ural Branch of Russian Science Academy for 2018.

\section{References}

1. Iu. B. Germeier, Games with Non-contradictory interests (Nauka, Moscow, p. 326, 1976)

2. A. V. Grebenkin, Proceedings of the 6th All-Russia Symposium on Economic Theory, Vol. 2. (Institute of Economics of Urals branch of RAS, Ekaterinburg, pp. 82-83, 2014)

3. V. E. Dementev, Journal of the New Economic Association, 2, 22 (2014) pp. 195-200.

4. S. Ermak, S. Ziakin, Ekspert, 43, 1005 (2016) pp. 80-102.

5. G. I. Idrisov, Industrial policy of Russian in present-day conditions (Gaydar Institute, Moscow, 2016)

6. Iu. Kniazev, (2015). Which Kind of Industrial Politics is in Need in Russia. Free Thought, No. 4 (1652), pp. 93-104.

7. B. V. Kuznetsov, Iu. V. Simachev, Journal of the New Economic Association, 2, 22 (2014) pp. 152-178.

8. A. N. Leontev, Bulletin of Volgograd branch of RANEPA. Political science and Sociology, 1 (2015) pp.16-20.

9. E. Moulin, theory with examples from mathematical Economics: translation from French (Mir, Moscow, p. 200, 1985)

10. V. M. Polterovich, Journal of the New Economic Association, 2, 22 (2014) pp.190-195.

11. N. M. Rozanova, V. S. Kokorin, Terra Economicus, 11, 3 (2013) pp. 20-33

12. O. A. Romanova, V. V. Akberdina, N. Iu. Bukhvalov, Bulletin of Baikal State Univeristy, 22, 8 (2016) pp. 126-136.

13. A. I. Tatarkin, O. A. Romanova, Economy of Region, 2 (2014) pp. 9-21.

14. A. Andreoni, Varieties of Industrial policy: Models, packages and transformation cycles (2016)

15. M. Cimoli, et al. Institutions and policies shaping industrial development: an introductory note (Lem Working paper series, 2006. - №. 2006/02)

16. L. Chen, B. Naughton, Research Policy 45, 10 (2016) pp. 2138-2152.

17. R. Devlin, C. Pietrobelli, Modern Industrial Policy and Public-Private Councils at the Subnational Level: Empirical Evidence from Mexico (Inter-American Development Bank, 2016)

18. D. Fudenberg, J. Tirole, Handbook of industrial Organization. T. 1 (pp. 259-327, 1989)

19. C. Hochfeld, et al, Sustainable Industrial Policy for Europe: Governing the Green Industrial Revolution (Green European Fundation, Brussels, 2010)

20. J. Hofbauer, K. Sigmund, Evolutionary games and population dynamics (Cambridge university press, 1998)

21. A. Noman, J. E. Stiglitz (ed.), Efficiency, Finance, and Varieties of Industrial Policy (Columbia University Press, 2016)

22. T. Rees, An introduction to evolutionary game theory (Technical report, pp. 1-4, 2005) 
23. Dani Rodrik, CEPR Discussion Paper, No. 4767 (2006)

24. Y. Tian, K. Govindan, Q. Zhu, Journal of Cleaner Production, 80 (2014) pp. 96-105.

25. J. W. Weibull, IUI Working Paper, No. 347 (1992)

26. Q. ZHU, Y. DOU, Systems engineering-theory \& practice, 27, 12 (2007) pp. 85-89. 